\title{
EDITORIAL
}

\section{Social Work and Social Welfare from a Multidisciplinary Perspective - A Challenge for Researchers}

\author{
Editor-in-Chief: Nicola Mucci, M.D., Ph.D.
}

In 2008, a deep economic crisis started in the US and rapidly spread around the world. The financial and economic crisis, called "The Great Recession", continues in many countries today and has been considered as the most severe recession in the history of US (after "The Great Depression"). The crisis brought very fast growth in unemployment and it is foreseeable that it will be long lasting and that recovery will be very slow. Hence, such economic change obviously had a significant impact on workers worldwide.

The crisis of the companies, with the staff cuts and the increase in the number of unemployed people, also resulted in significant changes in the work organization for those who remained in their job positions. The crisis increased job insecurity, in particular, for those who remained employed in industries where many layoffs had already occurred. In addition, the reduction in staff also led to stressful workplace conditions such as an increased workload with longer shifts and less rest, reduction of wages, and job dissatisfaction.

Considering the magnitude of "The Great Recession", this epochal moment can and must be a stimulus for a decisive rethinking of policies that allow an ever greater number of people to feel good and feel better.

Received: July 5, 2018; Accepted: July 6, 2018; Published: July 9, 2018

Correspondence to: Nicola Mucci, University of Florence, Florence, Italy; Email: nicola.mucci@unifi.it

Citation: Mucci N. Social Work and Social Welfare from a Multidisciplinary Perspective - A Challenge for Researchers. Soc Work Soc Welf, 2018, 1(1):1-3

Copyright: (C) 2018 Nicola Mucci.This is an open access article distributed under the terms of the Creative Commons Attribution License, which permits unrestricted use, distribution, and reproduction in any medium, provided the original author and source are credited.
The World Health Organization (WHO) defined health in its 1948 Constitution as Health is "a state of complete physical, mental and social wellbeing and not merely the absence of disease or infirmity". People are healthy when they are able to make choices, when they can exercise their substantial freedom, when they can achieve what they value, when they can express their potential, when they feel included in society, when they trust institutions, and when they feel supported in times of difficulty.

The welfare policies, even if marked by enormous differences between the different countries, represent a model of social coexistence based on solidarity. However, until today, welfare systems have developed in a context that no longer exists: constant economic growth, young working population, relatively homogeneous needs, solid family structures. The radical socio-economic changes in progress characterize today's welfare systems for their unsustainability, in particular from the economic-financial point of view, and their inadequacy, due to the inability to give effective answers to emerging social problems.

Therefore, in the current socio-economic context, it is necessary to adopt a new perspective that focuses on the person and its network of relationships rather than the types of services they need, adopting a logic of social inclusion and cohesion, with a view to building long-term strategies with a clear, transparent and concrete definition of strategic objectives.

The European Union, with the Europe 2020 
strategy, emphasizes the issue of social cohesion, to promote smart, sustainable and inclusive growth. The EU has set ambitious goals to be achieved by 2020 in the following five main areas:

- Employment: $75 \%$ of the population aged 20 to 64 must be employed;

- Innovation: $3 \%$ of EU gross domestic product (GDP) will have to be invested in research and development;

- Climate change: the "20/20/20" targets for climate and energy must be achieved (as well as reducing emissions by $30 \%$ if conditions are adequate).

- Education: the percentage of early school leavers must be less than $10 \%$ and at least $40 \%$ of those aged between 30 and 34 must have completed third-cycle studies or equivalent.

- Poverty: poverty reduction, with the aim of overcoming at least 20 million people the risk of poverty or exclusion.

Cohesion policy makes available the general investment framework and the allocation system necessary to achieve the objectives of the Europe 2020 strategy.

The proposed approach intends to promote an expansion of the conceptual framework of reference and of the traditional objectives of welfare: from a policy of assistance and acceptance of discomfort, to a policy for individual and collective well-being. In this way it is possible to go beyond the perspective of assistance, activating reciprocal practices that simultaneously produce social value and economic value, generating development.

Social cohesion commits the social forces as a whole: on one side the economic crisis has exacerbate the primary needs (employment, income, health, education, etc.); on the other they bring out new essential needs that must be satisfied to ensure the well-being of people: active relationships, exchanges, conditions of trust to produce and create value.

The concept is, therefore, that of a transforma- tion of social assistance services into actions of personal empowerment, where the subject is an active agent to be empowered and the need is sought to respond through the enhancement of potential. In order to be effective, social protection must have as its objective the capacity of the individual and therefore provide for his active participation in all cases in which this is realistically practicable.

Welfare today is facing a very difficult challenge: there is the strong need to rethink, with courage and realism, the entire social protection system, building new forms of system governance. In such a context, the work environment is one of the fundamental elements. In fact, within it can develop both opportunities for growth and development that risks to the health and safety of workers.

Today, it is no coincidence that the protection of health and safety is one of the most important aspects of global policies on employment and social affairs. The ongoing activities in this area involve a complex interaction between the various interlocutors, including governments and other public authorities, as well as associations of workers and employers.

The promotion of health and safety in the workplace is the result of joint efforts by employers, workers and society. The following factors contribute to the achievement of this goal: improving work organization and workplace; encouraging worker participation in the process regarding health promotion in the workplace; promoting healthy lifestyles and personal development (psychic, physical and relational).

Promoting health and safety in the workplace means more than simply meeting the legal requirements on health and safety, which are different in the various countries. Promoting health and safety in the workplace means above all that employers actively help their staff to improve overall health and well-being. Within this process it is essential to involve workers and take into account 
their needs and opinions on how to organize the activity and the workplace.

Improving wellbeing and health of workers leads to numerous positive consequences such as a lower staff turnover and less absenteeism, greater motivation and productivity, improvement of the image of the employer recognized as a positive organization and attentive to the wellbeing of the staff.

In recent years, the use of multidisciplinary methodologies and integrated in the management of health and safety in the workplace is emerging. In this sense, research, as well as greater productive efficiency, of the mutual adaptation of man and of the systems and means of production is a common goal of occupational medicine and occupational ergonomics. The synergistic coparticipation between the two disciplines in the design of shift systems represents, today, a need that is difficult to delegate. A similar integrated approach is applicable in any employment context. A careful risk assessment and a subsequent adoption of truly effective measures can bring benefits in terms of reducing injury risk and increasing productivity, as well as the health and safety benefits of workers. In this sense, measures to promote health and safety are more an opportunity than a cost for the employers.

A system aimed at the production of social welfare must be focused on optimizing the resources made available and aimed at maximizing the effect on the community of reference. With these premises, it is necessary that tools and services are constantly monitored in their impact. The optimization of resources allows to reach the maximum expression of the individual potential of the stakeholders and therefore to maximize the synergies and the establishment of virtuous efficiency circles on resources, as well as economic savings and the creation of guidelines.

Social Work and Social Welfare has ambitiously set itself the goal of becoming a point of reference for the scientific community that analyzes, under many points of view, the processes of social evolution and transformation all over the world. In particular, research fields of this Journal include, in non-exclusive way, the following topics: Social Resources; Social Policy and Law; Social Environment; Community System; Social Planing; Welfare System; Social Culture; Social Insurance; Public Welfare; Occupational Health; Social Medicine. 